\title{
STRENGTHENING HUMAN IMMUNE SYSTEM THROUGH PREDICTIVE DIET PLAN
}

\author{
Sunil Bhutada B. Samitha and Vignesh Pasula \\ Department of Information Technology, Sreenidhi Institute of Science Technology \\ Ghatkesar, Hyderabad. \\ sunilb@sreenidhi.edu.in, samhitha.kasyap@gmail.com
}

\begin{abstract}
:
Following an organic lifestyle can solve most of the problems in today's times. It helps in allows efficient use of resources; Organic farming tends to be better for the environment. One of the main reasons, based on which our project is developed is that It provides healthier food. Organic food is often fresher because it does not contain preservatives that make it last longer. The thought of developing this online shopping system to improve the overall health condition and educating people about organic farming. we have created a dashboard which provides various services for the benefit of the customer.
\end{abstract}

Keywords: Organic farming, online shopping, health, dashboard/website

\section{INTRODUCTION:}

Organic foods often have more beneficial nutrients, such as antioxidants, than their conventionally grown counterparts and people with allergies to foods, chemicals, or preservatives may find their symptoms lessen or go away when they eat only organic foods.

Most of the people around the world are addicted to junk food. Which has many side effects causing health issues.

In order to overcome these problems, On-line Organic product Shopping dashboard is developed. However, this is practically non-existent in India and in many Third World Countries. This is because of lack of appropriate knowledge of the organic farming and its benefits.

Eating junk food on a regular basis can lead to an increased risk of obesity and chronic diseases like cardiovascular disease.

Therefore, in order to avoid health deterioration this website promotes organic farming and its products.

\section{ONLINE SHOPPING}

The main reason for promoting organic products online is because using Internets interactive capabilities and providing relevant/customized information, organizations can attract new customers.

This traditional concept of a market is faced with diverse problems. These problems include:

- The essential need for buyers and sellers to come into physical contact to do their market activities

- The necessary need for potential buyers to visit the shop which may take a lot of time, money and discomfort

- Non-flexibility in time usage

In order to overcome these problems, On-line Shopping dashboard is developed.

\section{PROPOSED MODEL:}


As we realize that the world is in an immediate need for transforming its food habits from junk to organic products to maintain a healthy life, the thought is to develop a dashboard to buy and sell organic products.

The dashboard will contain three major sections: health predictor, organic foods and organic farming, respectively.

Anyone who is accessing the dashboard can either buy organic products such as raw material to grow plants without pesticides at home or directly purchase organic foods. Another special feature is the health predictor, the customer can answer the questionnaire to get a report on his health conditions.

it can freely provide the organic food diet and for the purchase of those suggested foods, there is an option of buying here itself.

\section{SYSTEM AND ARCHITECTURE:}

\subsection{System:}

Organic Farming is a web application where it can suggest the required organic foods based on the questioner the user fills. This application is build using python flask where python is the easiest and fastest way to run various algorithms and execute within the less time.

Flask is web development module available in python where enormous web applications can be built. For the front-end part, HTML, CSS JAVASCRIPT, BOOTSTRAP are used in this application.

The basic functions and features that the dashboard offers are when user will login/register or directly access the home page he gets to see three options namely Questionnaire, Buy Organic Foods, Buy Organic Products.

If the customer is interested to buy certain items, he can add those into the cart. Then he can add the payment method and proceed to pay to continue buying the products. After placing the order if interested the customer can then checkout from the website.

\section{MATERIAL \& METHODS:}

\subsection{Architecture}

Figure 1 shows the architectural structure of the website

The modules used are login screen, questionnaire, buy foods, buy products, health predictor, cart and checkout.

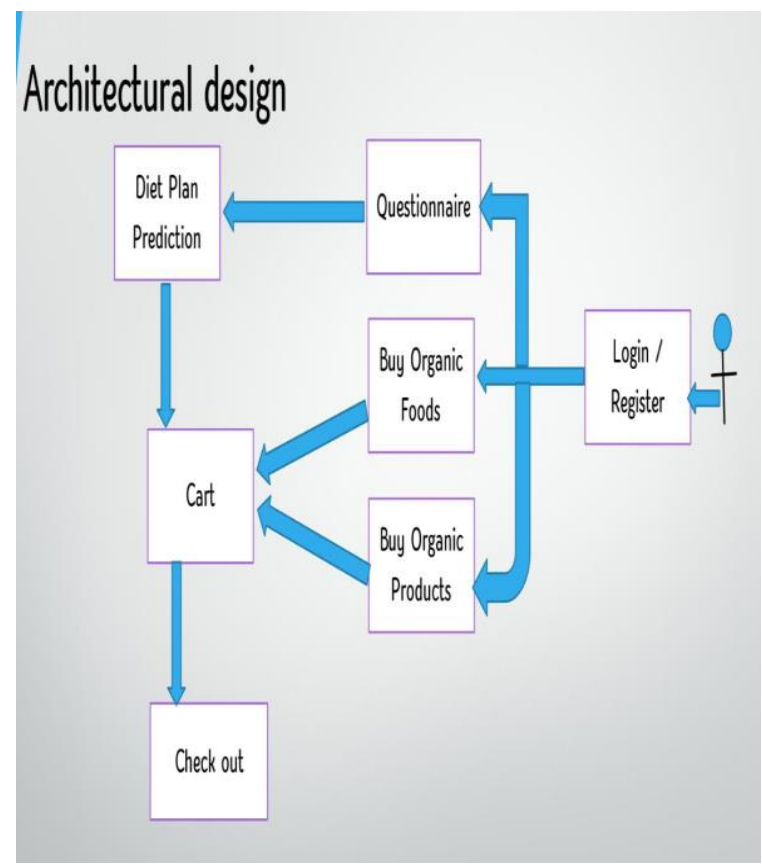

\section{Fig 1 : Architectural Design}

\section{a) Login Screen:}

The user will either register or login to use the application with the help of this module. This module helps the user to fill the personal details to maintain the details for further processes.

\section{b) Questionnaire :}

This is a module which contains a form with few simple questions which are helpful for predicting the diet plans.

* Sample questions are asked

* Data is collected using POST method

* Diet plan is suggested

* Buy suggested products 


\section{c) Buy Foods:}

This module will let the users to buy organic foods such as fruits, vegetables and millets which are available at reasonable prices.

\section{d) Buy Products:}

Buying other organic products like organic manure is also available from this place. This in turn promote the concept of terrace farming at home, thereby helping the environment.

\section{e) Diet Plan Prediction:}

This module which carries the diet plan prediction is this. Here the user will get the appropriate diet plan based on the inputs provided in the questionnaire.

\section{f) Cart:}

When the user is interested in buying, then the he will place the products in the cart. Here the whole price is calculated.

\section{g) Check out:}

This module is where the billing details are gathered and displayed to the user before exiting the cart.

\section{RESULTS \& DISCUSSION:}

\section{STEP 1:}

When the user enters the website he gets to see the Login Screen wherein he has to Login/Register to further use the services.

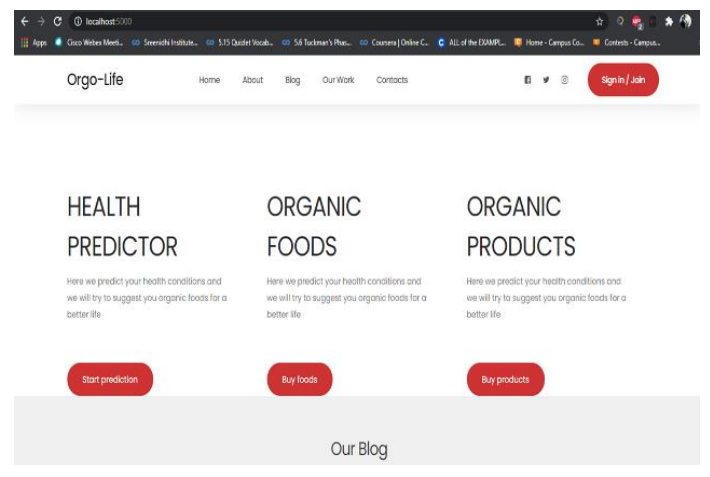

Fig 2: shows the dashboard options

\section{STEP2:}

Out of the three options the user can select any one to proceed with;

For instance if he chooses to predict his health he should answer the questions and upon doing so he receives a diet plan.

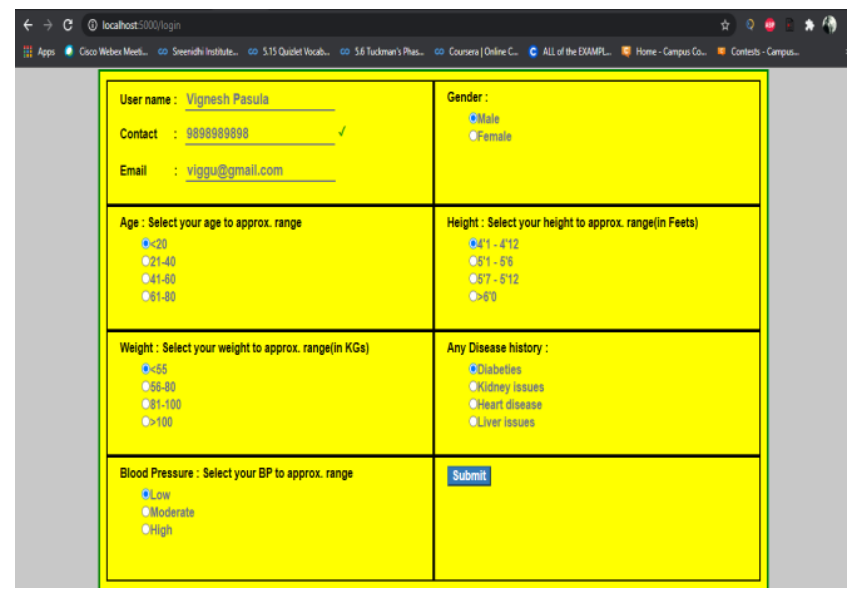

Fig 3: shows the list of questions

If the user chooses to buy foods then gets to select from the available items and add to cart 


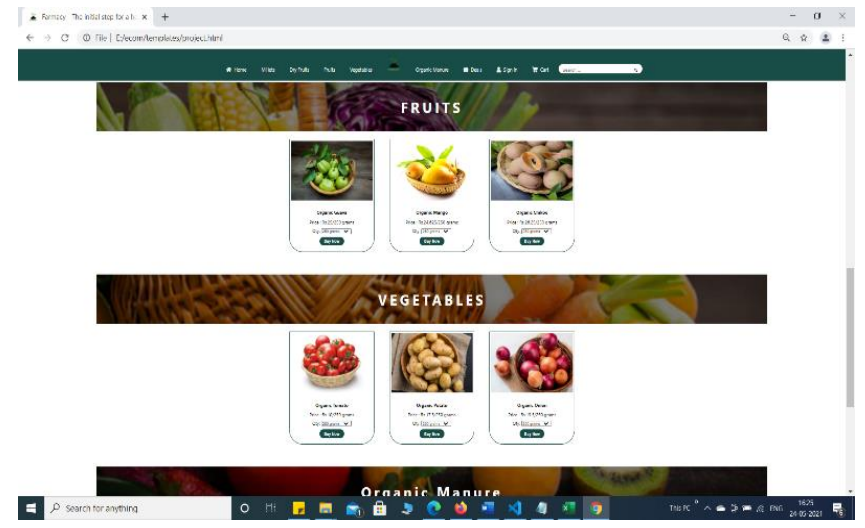

Fig 4: shows the available list of foods.

\section{FUTURE SCOPE AND CONCLUSION:}

We all agree that young generations are the future of the world, so it is especially important for them to maintain a proper health. Spreading knowledge and promoting an organic lifestyle is the key to achieve better health. Encouraging people to inculcate organic food or products into their lives is the primary step to a greater development of overall health.

This application can be further developed and converted to a mobile application where the it can alert the user not to miss their diet according to the time set by the user himself.

Remainders will be thought provoking and can be helpful for the elderly people.

\section{REFERENCES:}

P.J. Mahesh, Minhas Naheem, Razak Mubafar, S Shyba, Sunitha Beevi. (2016). New aspect for organic farming practices: Controlled crop nutrition and soilless agriculture, IEEE Global Humanitarian Technology Conference (GHTC). Elpawati. (2018). Design and Build of Information System on E-Commerce of Organic Waste Decomposer and Plant Fertilizer EM-10 (Effective Microorganism-10) by Yuni Sugiarthi. 6th International Conference on Cyber and IT Service Management (CITSM).

Reiner Dumke, Andreas Schmietendorf. (2010). Organic Product Catalogs: Towards an rchitecture for Cloud-Based Micro Enterprise E-commerce by Robert Neumann. IEEE 3rd International Conference on Cloud Computing. Natalia Porplytsya, Maryna Nagara. (2020). Mathematical Model for Prediction the Dynamics of Organic Traffic at E-commerce Web-site in the Process of its Search Engine optimization by Irina Madiudia. 10th International Conference on Advanced Computer Information Technologies (ACIT).

Jiabao Lin, Ofir Turel, Shan Liu. (2020). purchasing organic food with social commerce: An integrated food-technology consumption values perspective by Jinyuan Guo. International Journal of Information Management Volume 51, 102033.

Junjun Gao. (2020). Research on the Network Marketing Model of Agricultural Products under the Background of "Internet +". International Conference on E-Commerce and Internet Technology (ECIT).

Ahelam Tikotikar, Mallikarjun Kodabagi. (2017). A survey on technique for prediction of disease in medical data. International Conference on Smart Technologies for Smart Nation (SmartTechCon).

Sneha Grampurohit, Chetan Sagarnal. (2020). Disease Prediction using Machine Learning Algorithms, International Conference for Emerging Technology (INCET).

Roger Lee, Chinmayi Chitnis. (2018). Improving Health-Care Systems by Disease Prediction. International Conference on Computational Science and Computational Intelligence (CSCI). Feixiang Huang, Shengyong Wang, Chien-Chung Chan. (2012). Predicting disease by using data mining based on healthcare information system. IEEE International Conference on Granular Computing 
I J R B A T, Issue (IX), Vol. II, May 2021: 56-59

A Double-Blind Peer Reviewed \& Refereed Journal
e-ISSN $2347-517 X$

Original Article 